\title{
Psychotic Reactivity to Daily Life Stress and the Dopamine System: A Study Combining Experience Sampling and [F-18] fallypride Positron Emission Tomography
}

Citation for published version (APA):

Hernaus, D., Collip, D., Lataster, J., Viechtbauer, W., Myin, E., Ceccarini, J., Van Laere, K., van Os, J., \& Myin-Germeys, I. (2015). Psychotic Reactivity to Daily Life Stress and the Dopamine System: A Study Combining Experience Sampling and [F-18] fallypride Positron Emission Tomography. Journal of Abnormal Psychology, 124(1), 27-37. https://doi.org/10.1037/abn0000010

Document status and date:

Published: 01/02/2015

DOI:

10.1037/abn0000010

Document Version:

Publisher's PDF, also known as Version of record

\section{Document license:}

Taverne

\section{Please check the document version of this publication:}

- A submitted manuscript is the version of the article upon submission and before peer-review. There can be important differences between the submitted version and the official published version of record. People interested in the research are advised to contact the author for the final version of the publication, or visit the $\mathrm{DOI}$ to the publisher's website.

- The final author version and the galley proof are versions of the publication after peer review.

- The final published version features the final layout of the paper including the volume, issue and page numbers.

Link to publication

\footnotetext{
General rights rights.

- You may freely distribute the URL identifying the publication in the public portal. please follow below link for the End User Agreement:

www.umlib.nl/taverne-license

Take down policy

If you believe that this document breaches copyright please contact us at:

repository@maastrichtuniversity.nl

providing details and we will investigate your claim.
}

Copyright and moral rights for the publications made accessible in the public portal are retained by the authors and/or other copyright owners and it is a condition of accessing publications that users recognise and abide by the legal requirements associated with these

- Users may download and print one copy of any publication from the public portal for the purpose of private study or research.

- You may not further distribute the material or use it for any profit-making activity or commercial gain

If the publication is distributed under the terms of Article $25 \mathrm{fa}$ of the Dutch Copyright Act, indicated by the "Taverne" license above, 


\title{
Psychotic Reactivity to Daily Life Stress and the Dopamine System: A Study Combining Experience Sampling and $\left[{ }^{18}\right.$ F]fallypride Positron Emission Tomography
}

\author{
Dennis Hernaus and Dina Collip \\ Maastricht University
}

\author{
Wolfgang Viechtbauer \\ Maastricht University
}

Jenny Ceccarini and Koen Van Laere
University Hospital Louvain and Catholic
University Louvain

\author{
Johan Lataster \\ Open University Heerlen and \\ Maastricht University \\ Erik Myin \\ University of Antwerp
}

\author{
Jim van Os and Inez Myin-Germeys \\ Maastricht University
}

\begin{abstract}
Stressful life events increase the risk for psychosis, and the subjective experience of stress related to daily life activities drives moment-to-moment variation in psychotic intensity. Positron emission tomography (PET) studies suggest that dopaminergic (DAergic) activity mediates the behavioral response to an experimental stressor. However, it is not known how alterations in this DAergic stress response relate to the subjective experience of stress in real life situations assessed in momentary assessment studies. This study combined $\left[{ }^{18} \mathrm{~F}\right]$ fallypride PET with an Experience Sampling ambulatory assessment approach to examine the association between the prefrontal DAergic response to experimentally induced stress and real life psychotic reactivity to the subjective experience of stress in daily life. Healthy first-degree relatives of individuals with a psychotic disorder $(N=14)$ and healthy controls $(N=11)$ participated in (a) a psychosocial $\left[{ }^{18} \mathrm{~F}\right]$ fallypride PET stress paradigm and (b) an experience sampling study, using a structured diary approach. Mixed multilevel random intercept models revealed that stress-induced $\left[{ }^{18} \mathrm{~F}\right]$ fallypride displacement, indicative of DAergic activity, in ventromedial prefrontal cortex (VMPFC) was associated with psychotic reactivity to daily life stress in the entire sample. Lower levels of $\left[{ }^{18} \mathrm{~F}\right]$ fallypride displacement to stress predicted increased psychotic reactivity to daily life stress. This study combined PET neuroimaging with real life behavioral assessments in the investigation of psychotic symptoms; we showed decreased $\left[{ }^{18} \mathrm{~F}\right]$ fallypride displacement to stress in VMPFC to be associated with increased psychotic reactivity to daily life stress. The preliminary evidence in this study demonstrates that it is possible to acquire a grasp on how brain function is associated with contextualized experience, which has relevance for neuroimaging studies in general.
\end{abstract}

Keywords: PET, psychosis, ESM, stress, dopamine

Dennis Hernaus and Dina Collip, Department of Psychiatry and Psychology, South Limburg Mental Health Research and Teaching Network, EURON, Maastricht University; Johan Lataster, Faculty of Psychology and Educational Sciences, Open University Heerlen and Department of Psychiatry and Psychology, South Limburg Mental Health Research and Teaching Network, EURON, Maastricht University; Wolfgang Viechtbauer, Department of Psychiatry and Psychology, South Limburg Mental Health Research and Teaching Network, EURON, Maastricht University; Erik Myin, Centre for Philosophical Psychology, University of Antwerp; Jenny Ceccarini and Koen Van Laere, Division of Nuclear Medicine, University Hospital Louvain and Department of Imaging and Pathology, Catholic University Louvain; Jim van Os and Inez MyinGermeys, Department of Psychiatry and Psychology, South Limburg Mental Health Research and Teaching Network, EURON, Maastricht University.

We thank Wendy Beuken, Rufa Diederen, Stijn Dirix, Truda Driesen, Bernice Gulpers, Kwinten Porters, and Mieke Steukers for their assistance with data-collection, the PET radiopharmacy team for their skilled tracer preparation and Ron Mengelers for technical support. IMG was supported by a 2006 NARSAD Young Investigator Award and by a VIDI grant from the Dutch Medical Research Council. She also is supported by an ERC consolidator grant (ERC-2012-StG, project 309767 - INTERACT). KV is Senior Clinical Investigator for the Flemish Fund for Scientific Research (FWO). DC is supported by a Maastricht University postdoc Kootstra fellowship. EM is supported by the Research Foundation Flanders (FWO). JVO is or has been an unrestricted research grant holder with, or his institution has received financial compensation as an independent symposium speaker from, Eli Lilly, BMS, Lundbeck, Organon, Janssen, GlaxoSmithKline, AstraZeneca, Pfizer, and Servier. Data presented in this article is available to collaborators upon request.

Correspondence concerning this article should be addressed to Inez Myin-Germeys, Department of Psychiatry and Psychology, Maastricht University, PO Box 616 (VIJV), 6200 MD Maastricht, The Netherlands. E-mail: i.germeys@maastrichtuniversity.nl 
In recent years, functional neuroimaging has allowed investigation of changes in neurotransmitter systems associated with conversion (Howes et al., 2011a; Howes et al., 2011b), symptoms (Howes et al., 2011b; Kegeles et al., 2008), and treatment efficacy/ response (Demjaha, Murray, McGuire, Kapur, \& Howes, 2012; Howes et al., 2012) in psychotic disorder. Furthermore, ecological assessment strategies such as the experience sampling method (ESM) have proven to be essential in demonstrating how psychotic symptoms fluctuate as a function of person-environment interactions (Collip et al., 2013b; Lataster, Valmaggia, Lardinois, van Os, \& Myin-Germeys, 2013), sparking new insights for therapy (Kramer et al., 2013; So, Peters, Swendsen, Garety, \& Kapur, 2013). However, given that mental disorders involve both brain and behavior, research integrating both factors is required to grasp the complex ways in which they are related.

In the context of psychosis, the role of stressful events (e.g., childhood trauma and severe life events) in the development of symptoms (Varese et al., 2012) and the neural mechanisms involved (van Winkel, Stefanis, \& Myin-Germeys, 2008) have been in the spotlight in the last decade. Stressful events have been identified as a major risk factor for psychosis (Read, Perry, Moskowitz, \& Connolly, 2001; Walker \& Diforio, 1997) and may precede and predict the onset of psychotic symptoms (Heins et al., 2011; Kelleher et al., 2013; Read et al., 2001).

Using ESM, a similar momentary increase in (subclinical) psychotic symptoms has been observed after the experience of (minor) daily life stresses in patients with psychotic disorder (Lataster, Collip, Lardinois, van Os, \& Myin-Germeys, 2010; MyinGermeys, Delespaul, \& van Os, 2005a) and individuals at increased genetic risk of psychosis (Myin-Germeys et al., 2005a). That even the experience of minor stressful events are able to exacerbate psychotic intensity underlines the strong relation between environmental stress and psychosis.

When studying stress, one can distinguish the objective environmental trigger, the subjective appraisal of how stressful this event or activity is to the person, and the effect of this subjectively appraised stress on mood and symptomatology. In the ESM studies reviewed above, rather than studying the relationship between objective event and subjective stress appraisal, the relation between the subjective stress appraisal and changes in mood or psychotic symptom intensity were assessed, called emotional or psychotic reactivity to stress (Myin-Germeys \& van Os, 2007). Previous structured diary studies have repeatedly observed significant psychotic reactivity to the subjective experience of daily stress (Myin-Germeys et al., 2005a; Myin-Germeys \& van Os, 2007) and this stress reactivity is thought to be a central characteristic of vulnerability to psychosis (Myin-Germeys \& van Os, 2007). Therefore, in the current manuscript, we will focus on the momentary assessment of psychotic experiences in response to the subjective experience of stress in daily life.

Positron emission tomography (PET) has been used to demonstrate that increased striatal dopaminergic (DAergic) activity is a hallmark feature of psychosis (Howes \& Kapur, 2009) and is positively associated with illness phases and symptoms of the disorder (Laruelle \& Abi-Dargham, 1999; Laruelle, Abi-Dargham, Gil, Kegeles, \& Innis, 1999). More recent studies seem to suggest that the locus of these changes in the dopamine (DA) system is the associative part of the striatum (Egerton et al., 2013; Kegeles et al., 2010; Mizrahi et al., 2012).
The DA system also plays an important role in the stress response, suggesting a neurobiological mechanism for the association between the subjective experience of stress and psychosis. PET studies in humans using a well-validated arithmetic stressor (Montreal Imaging Stress Task [MIST]) have revealed that increased DA release in the (associative) striatum of patients (Mizrahi et al., 2012) and individuals at (ultrahigh) risk of developing psychosis can be observed when exposed to a stressor (Mizrahi et al., 2012; Soliman et al., 2008), whereas DA release in the striatum of healthy volunteers (HV) is variably affected by the same stressor (Montgomery, Mehta, \& Grasby, 2006; Pruessner, Champagne, Meaney, \& Dagher, 2004).

Although the majority of DA receptors are located in the striatum, recent evidence suggests that changes in extrastriatal DA release after exposure to a stressor can also be observed (Lataster et al., 2014; Nagano-Saito et al., 2013). Importantly, HV and first-degree relative of individuals with psychotic disorder $(\mathrm{HR}+)$ display differences in the prefrontal cortex (PFC) DAergic stress response: although there is a positive correlation between stressinduced PFC DA release and both physiological parameters and subjectively experienced stress (Lataster et al., 2011; NaganoSaito et al., 2013) in HV, stress-induced PFC DA release decreases as subjectively experienced stress increases in $\mathrm{HR}+$ (Lataster et al., 2014). The above mentioned results indicate that the subjective experience of stress, psychosis, and the DA system are tightly coupled, and it is therefore, expected that this neurotransmitter system plays an essential role in psychotic reactivity to daily life stress, as observed with ESM.

Investigating the role of DA in dynamic person-environment interactions is difficult as it requires a lab setting, whereas psychotic reactivity to daily life stress is a real life phenomenon. Attempts to overcome these methodological difficulties have been made. Myin-Germeys and colleagues (Myin-Germeys, Marcelis, Krabbendam, Delespaul, \& van Os, 2005b), for example, investigated the association between homovanillic acid (HVA), a proxy of DAergic activity, and psychotic reactivity to daily life stress. In this study, they demonstrated that elevated levels of HVA, possibly indicating increased (striatal) DAergic activity, were associated with increased psychotic reactivity to daily life stress. Unfortunately, HVA is a catecholaminergic metabolite, mostly reflecting peripheral and central noradrenaline activity (Kopin, Bankiewicz, \& Harvey-White, 1988), and therefore, an unspecific indicator of central DAergic activity, providing no information regarding brain processes associated with psychotic reactivity to daily life stress.

An alternative approach to investigate the involvement of the DA system in psychotic reactivity to daily life stress is by combining the strengths of PET and ESM. We (Lataster et al., 2014) and others (Mizrahi et al., 2012; Pruessner et al., 2004) have shown that a PET design using a dopaminergic radioligand and a stress-inducing paradigm such as the MIST (Pruessner et al., 2004) can be reliably used to investigate DA release in response to a stressor. Using the ESM in the same individuals may provide insights into plausible links between dynamics of brain processes and experiences resulting from real life situations. This approach is motivated by the idea that, fundamentally, brain processes should be, and can only be, understood in terms of the contextualized person-environment interactions that they play a role in.

In the current study, a PET-ESM design was used to study our main research question: is the PFC DAergic stress response, as 
assessed with $\left[{ }^{18} \mathrm{~F}\right]$ fallypride PET, associated with psychotic reactivity to daily life stress, as assessed with ESM? For this purpose, a sample of $\mathrm{HV}$ and $\mathrm{HR}+$ that previously participated in a PET study investigating the DAergic stress response in the PFC (Lataster et al., 2014) completed a 6-day ESM study to assess their psychotic reactivity to daily life stress. Based on previous work (Lataster et al., 2014), we hypothesized that lower stress-induced $\left[{ }^{18} \mathrm{~F}\right]$ fallypride displacement in the PFC would be associated with increased psychotic reactivity to daily life stress. Because HR+ are known to react more strongly to daily life stress than HV (Collip et al., 2011; Myin-Germeys et al., 2005b), we expected a stronger correlation between psychotic reactivity to daily life stress and stress-induced $\left[{ }^{18} \mathrm{~F}\right]$ fallypride displacement in $\mathrm{HR}+$ than $\mathrm{HV}$.

\section{Method}

\section{Sample}

The sample consisted of 25 individuals who were not diagnosed with mental illness: 14 healthy first-degree relatives of individuals with a psychotic disorder $(\mathrm{HR}+)$ and 11 healthy individual without any first-degree relatives with psychotic disorder (HV). Inclusion criteria were (a) age 18-65 years and (b) sufficient command of the Dutch language to understand instructions and provide informed consent. Exclusion criteria were (a) a first- or second degree relative with a diagnosis of a psychotic disorder (for HV), (b) presence or history of psychiatric illness, (c) head trauma with loss of consciousness ( $>5 \mathrm{~min}$ )/central neurological disorder, (d) endocrine disorder, (e) cardiovascular disorder, (f) current use of psychotropic medication, (g) current/previous misuse of illicit drugs, (h) $>5$ standard units of alcohol per day, (i) metal elements in the body, (j) claustrophobia, or (k) pregnancy or lactation. Mental disorders (exclusion Criterion b) were assessed using the Operational Criteria Checklist for Psychotic Illness (OCCPI). Checklist outcomes were analyzed with the OPCRIT computerized program (McGuffin, Farmer, \& Harvey, 1991) and were matched against International Classification of Diseases and Related Health Problems (ICD-10) and Diagnostic and Statistical Manual of Mental Disorders-Fourth Edition (DSM-IV) (American Psychiatric Association, 2000) criteria. The standing medical ethics committee of Maastricht University approved the study. Participants provided written informed consent before taking part. All individuals were treated in accordance with APA ethical standards.

\section{Ecological Assessment: The Experience Sampling Method}

Methodology. The ESM is a within-day self-assessment technique. Previous applications of ESM have demonstrated its feasibility in general population and patients samples, as well as the reliability of the selected items.(Myin-Germeys et al., 2005a; Myin-Germeys, van Os, Schwartz, Stone, \& Delespaul, 2001). Participants received a digital wristwatch and a set of ESM selfassessment forms collated in a booklet for each day. Ten times a day on six consecutive days, the watch emitted a signal (beep) at unpredictable moments between 7:30 a.m. and 10:30 p.m. After each "beep," reports of thoughts, current context (activity, persons present, or location), appraisals of the current situation, current subclinical psychotic experiences (Linscott \& van Os, 2013), and mood were collected.

The ESM procedure was explained to participants during an initial briefing session and a practice form was completed to confirm that participants were able to understand and use the methodology. Participants were instructed to complete their reports immediately after the prompt; thus, minimizing memory distortions, and to record the time at which they completed the form. These times were compared with the actual time of the prompt, as programmed in the digital wristwatch.

All reports completed more than 15 min after the actual signal were excluded from the analysis. Previous work (Delespaul, 1995) has shown that reports completed after this interval are less reliable and consequently less valid. Participants with less than 20 valid reports were excluded from the analysis. During the actual sampling period, research staff contacted participants by telephone to verify compliance with the instructions.

Measures of daily life stress and psychotic experiences. Two parameters were included in the analyses. These were the momentary assessment of the subjective experience of stress related to daily activities (operationalized here as "daily life stress") and the momentary assessment of psychotic symptoms. In accordance with previous research (Lataster et al., 2010; Myin-Germeys et al., 2005a; Myin-Germeys et al., 2001), daily life stress was conceptualized as the appraised stressfulness of activities in the natural flow of daily life ("activity-related stress"). Daily life stress was assessed with three items, rated on a 7-point Likert scale (rating from not at all $[=1]$ to very $[=7])$ ). The three items used were: "I am not skilled to do this activity"; "This activity requires effort"; and "I would rather do something else" (Cronbach's $\alpha$ of .52 in a sample of; Myin-Germeys et al., 2005a; Myin-Germeys et al., 2005b). These items assessed the appraised stressfulness of the activity participants were engaged in just before the watch emitted its signal. This experience of subjective stress was not restricted to a selection of events; all prompts were taken into account. Furthermore, the objective stressor, the event, was not taken into account, motivated by the idea that the experiential meaning of an event depends on the person's appraisal of and sensitivity to the event. Momentary subclinical psychotic experiences were assessed using the mean score of a set of nine items, rated on a 7-point Likert scale: "I feel suspicious"; "I feel unreal"; "I feel that others dislike me"; "I feel that others want to hurt me"; "My thoughts are influenced by others"; "I am afraid to lose control"; "I can't get these thoughts out of my head"; "I hear voices"; and "I see things that aren't really there" (Cronbach's $\alpha$ of .8 in a sample of 139 ; Myin-Germeys et al., 2005a). Items were selected to reflect positive psychotic experiences, that is, hallucinations and delusions, guided by previous literature (Myin-Germeys et al., 2005a; MyinGermeys et al., 2009; Peerbooms et al., 2012).

\section{Positron Emission Tomography}

Psychosocial stress challenge. The MIST (Lataster et al., 2011; Pruessner et al., 2004) is a PET-adapted version of the Trier Mental Challenge Task (Kirschbaum, Pirke, \& Hellhammer, 1993). Its details and effects on the DA system have been described in detail elsewhere (Hernaus et al., 2013; Lataster et al., 2014; Pruessner et al., 2004). 
Briefly, the task consisted of a control and experimental condition. During the control condition, participants performed 6-min blocks of mental arithmetic on a computer screen without time constraints or performance feedback. In the stress condition, participants performed similar mental arithmetic as in the control condition, with the addition of information about the total number of errors, expected average number of errors, time spent on current problem, a tone rising in frequency indicating the end of the response interval, and evaluative feedback of a confederate investigator. This manipulated performance in the stress condition was matched to unrealistic standards.

PET acquisition. The acquisition protocol used for the purposes described in the manuscript has been described in detail in previously published work (Hernaus et al., 2013; Lataster et al., 2011). In short, $\left[{ }^{18} \mathrm{~F}\right]$ fallypride is a high affinity $D_{2 / 3}$ radiotracer (Mukherjee et al., 2002) used for striatal and extrastrial areas (Ceccarini et al., 2012; Hernaus et al., 2013; Lataster et al., 2014; Woodward et al., 2011). The high affinity for the $D_{2 / 3}$ receptor yields high signal to noise ratio, making it suitable to investigate DAergic activity in extrastriatal areas, where the density of these receptors is an order of magnitude lower than in the striatum (Hall, Farde, \& Sedvall, 1988). $\left[{ }^{18} \mathrm{~F}\right]$ fallypride $(M=183.22 \mathrm{MBq}, S D=$ 7.63) was administered in a slow intravenous bolus injection through a catheter in the antecubital vein. Emission data were collected using a single infusion protocol consisting of two segments; a MIST control condition (0-70 min) and MIST stress condition (100-166 min) (Ceccarini et al., 2012; Christian et al., 2006; Hernaus et al., 2013; Lataster et al., 2011). There was a brief 10-min break between the control and experimental segment. Dynamic emission scans were collected in three-dimensional (3D) mode using a HiRez Biograph 16 PET/computed tomography (CT) camera (Siemens Medical Solutions, Inc., Munich, Germany). A low-dose $(80 \mathrm{kV}$ tube potential, $11 \mathrm{~mA} \cdot \mathrm{s}) \mathrm{CT}$ scan was obtained to later correct for movement throughout the paradigm; one at the start of each PET segment and one at the end of the emission scan. Images were reconstructed using a 3D ordered-subset expectation maximization (OSEM) iterative reconstruction including modelbased scatter and attenuation correction based on a measured attenuation map acquired by the $\mathrm{CT}$, with a final spatial resolution of $4 \mathrm{~mm}$. For each participant, a T1-weighted and standard transverse T2 brain magnetic resonance image (MRI; 1.5 Tesla Vision Scanner, Siemens, Germany) was obtained. Parameters for the T1 3D Magnetization Prepared Rapid Acquisition Gradient Echo sequence were: $\mathrm{TR}=0 \mathrm{~ms}$, TE $=4 \mathrm{~ms}$, flip angle $=12^{\circ}$, inversion time $=300 \mathrm{~ms}$, matrix $=256 \times 256,160$ sagittal contiguous slices of $1 \mathrm{~mm}$. Realignment, coregistration to MRI, normalization (T1-weighted Montreal Neuroimaging Institute [MNI] template) and smoothing ( $4 \mathrm{~mm}$ full width half maximum [FWHM]) of PET data was performed before applying the kinetic model using SPM8 (http://www.fil.ion.ucl.ac.uk/spm) (Hernaus et al., 2013; Lataster et al., 2014).

The kinetic model. For each participant, VOI-based analyses were performed to estimate the kinetic parameters using the linear simplified reference region model (LSRRM) and PET timeactivity curves (TACs). The LSRRM makes use of a single infusion design to obtain assessments of neurotransmitter activity, preventing possibly noisy subtraction of two low binding potential relative to nondisplaceable radioligand $\left(\mathrm{BP}_{\mathrm{ND}}\right)$ values in extrastriatal regions and limiting within-subject variability, given that such assessments are susceptible to noise and may reduce sensitivity to detect significant changes in DAergic activity (Ceccarini et al., 2012; Hernaus et al., 2013; Lataster et al., 2011). This is especially relevant for indices of extrastriatal DAergic areas, where $D_{2 / 3}$ receptors are an order of magnitude lower than in the striatum. A detailed description of the kinetic model parameters in this sample was provided elsewhere (Ceccarini et al., 2012; Hernaus et al., 2013; Lataster et al., 2011).

In short, the LSRRM yields statistical parametric voxel-wise t-maps of the "activation" parameter $\gamma(t=\gamma / \operatorname{sd}(\gamma)$, where $S D(\gamma)$ is the $S D$ parametric value for $\gamma$. In this case, $\gamma$ is assumed to reflect a quantification of the amount of DAergic activity in response to an experimental stimulus. The spatial extent of the estimated stress-induced ligand displacement was presented as the proportion of voxels within a given VOI exceeding a threshold $t>$ 4.5 , which corresponds to a $p<.000002$ one-tailed $t$ test comparing increased ligand displacement versus the control state, or a false discovery rate (FDR)-corrected $p<.05 t$ test (Hernaus et al., 2013; Lataster et al., 2014). The spatial extent of ligand displacement in the left and right ventro-medial prefrontal cortex (VMPFC) (BA10) was investigated, as this area has been documented to play an important role in the DAergic stress response (Lataster et al., 2011; Nagano-Saito et al., 2013). The cerebellum served as a reference region (Lammertsma \& Hume, 1996). The regions were based on the anatomical delineation of the human PFC. Masks were based on the corresponding normalized individual MRI, using the Talairach atlas (Talairach \& Tournoux, 1988).

\section{Statistical Analyses}

Analyses were carried out in Stata (StataCorp. 2011. Stata Statistical Software: Release 12. College Station, TX: StataCorp LP). ESM data are hierarchical in nature, as multiple observations (Level 1) are nested within participants (Level 2). Therefore, hierarchical linear models were used, which take into account that residuals are not independent, given that observations from the same participant are more similar than observations from different participants (Schwartz \& Stone, 1998). Because the distribution of (momentary) subclinical psychotic experiences in the general population is severely skewed to the right, multilevel analyses containing this dependent variable were carried out using the Stata xtmelogit multilevel logistic regression routine, yielding odds ratios (OR). For this purpose, momentary subclinical psychotic experiences were dichotomized (momentary psychosis $=0$ if mean score $=1$, momentary psychosis $=1$ if mean score $>1$ ).

The strength of logistic regression is that the model does not assume a specific (linear) distribution of the dependent variable, hence it is robust against potentially skewed distributions of the dependent variable. Momentary daily life stress, however, was normally distributed; therefore, the xtmixed multilevel linear regression routine was used for analyses with daily life stress as dependent variable.

First, group differences (HR + vs. HV) in momentary subclinical psychotic experiences (using multilevel logistic regression) and momentary levels of daily life stress (using multilevel linear regression) were investigated with group status as independent variable. Second, interaction analyses were performed to investigate the association between psychotic reactivity to daily life stress and stress-induced $\left[{ }^{18} \mathrm{~F}\right]$ fallypride displacement. The effects of 
momentary daily life stress and stress-induced $\left[{ }^{18} \mathrm{~F}\right]$ fallypride displacement as well as their interaction were estimated in the model of momentary psychosis. Third, in an exploratory analysis, given low power, group was added to examine the three-way interaction between momentary daily life stress, stress-induced $\left[{ }^{18} \mathrm{~F}\right]$ fallypride displacement and group status in the model of momentary psychosis.

All variables were continuously distributed, except for momentary psychotic experiences ( 0 or 1 ) and group status (HV or HR + ). Task-induced $\left[{ }^{18} \mathrm{~F}\right]$ fallypride displacement was quantified as the proportion of voxels exceeding Bonferroni-corrected significance threshold of $p(\alpha(\mathrm{FDR})=5 \%)<.05)$ in the VMPFC, an index of DAergic activity in response to stress (Hernaus et al., 2013; Lataster et al., 2011). To investigate if ESM variables were also associated with indices of the DA system not necessarily associated with psychological stress; we repeated interaction analyses with $\mathrm{BP}_{\mathrm{ND}}$ (Innis et al., 2007) calculated over the complete paradigm (Hernaus et al., 2013; Lataster et al., 2014). In all analyses, age and sex were entered as nuisance covariates.

Random intercept and random intercept + random slope models were carried out for all multilevel models. Random intercept models were used to reflect a liberal threshold for detecting associations (potentially prone to Type I errors), whereas random intercept + random slope models were used as a conservative threshold. In light of the sample size, the latter models were prone to Type II errors. Independent variables with multilevel structure were used to estimate the random slope in random intercept + random slope models. Covariance structure was set to unstructured. A Bonferroni-corrected threshold of $p=.025$ (left/right VMPFC, 2 comparisons) was used for interaction analyses.

\section{Results}

\section{Main Effects}

There were no significant differences between $\mathrm{HR}+$ and $\mathrm{HV}$ in age $(\mathrm{HV}[M=38.55, S D=15.85], \mathrm{HR}+[M=41, S D=14.62])$, gender (HV [8 males, 3 females], HR+ [7 males, 7 females], education, maternal/paternal education, work status, marital status, smoking, alcohol consumption, and injection parameters (previously published in Hernaus et al., 2013; Lataster et al., 2014). We have previously reported that stress-related $\left[{ }^{18} \mathrm{~F}\right]$ fallypride displacement in this sample is not associated with age (Hernaus et al., 2013) and that there is no group difference in stress-related $\left[{ }^{18} \mathrm{~F}\right]$ fallypride displacement or $\mathrm{BP}_{\mathrm{ND}}$ (Lataster et al., 2014). On average, HV completed 45 valid prompts $(S D=10)$ and $\mathrm{HR}+$ completed 53 valid prompts $(S D=5.11)$ (n.s.). Females $(M=55$, $S D=2.6)$ completed more valid prompts than males $(M=46$, $S D=9.35)(\mathrm{Z}=-9.34 ; \mathrm{B}=-12.05 ; 95 \%$ CI $[-14.58$ to -9.52 ]; $p=.01)$. Overall, 61 invalid completed prompts were excluded (see Methodology) (4.82\% of total). No participants were excluded because of a too low number of completed valid prompts. The average number of invalid completed prompts was $2.23(S D=$ 2.67). Although the number of excluded completed prompts was low, more completed prompts were excluded from $\mathrm{HV}(M=3.76$, $S D=3.25)$ than $\mathrm{HR}+(M=1.26, S D=1.6)(\mathrm{T}=-2.59$; $\mathrm{B}=-2.9 ; 95 \% \mathrm{CI}[-5.2$ to -.59$] ; p=.02)$. HV experienced more daily life stress than $\mathrm{HR}+$ (random intercept: $\mathrm{Z}=-3.17$; $\mathrm{B}=-.48 ; 95 \% \mathrm{CI}[-.77$ to -.18$] ; p<.01$; random intercept + slope: identical). There were no group differences in momentary subclinical psychotic experiences (random slope: $\mathrm{Z}=.77$; $\mathrm{B}=$ $.67 ; 95 \%$ CI $[-1.02$ to .2 .33$] ; p=.44$; random slope + intercept: $\mathrm{Z}=.76 ; \mathrm{B}=.65 ; 95 \% \mathrm{CI}[-1.02$ to -2.31$] ; p=.45)$.

\section{The Association Between Stress-Induced $\left[{ }^{18}\right.$ F]fallypride Displacement (PET) and Psychotic Reactivity to Daily Life Stress (ESM)}

As displayed in Table 1, random intercept models revealed that stress-induced $\left[{ }^{18} \mathrm{~F}\right]$ fallypride displacement in right VMPFC moderated the association between momentary daily life stress and momentary subclinical psychotic experiences. The moderation effect for the left VMPFC failed to reach significance at the conventional threshold. Significant results were not observed for random intercept + random slope models (see Table 1), although the direction was similar to random intercept models. Odds ratios for right VMPFC and left VMPFC were .43 (95\% CI [2 to .91]) and .51 (95\% CI [.25 to 1.02$]$ ), respectively (see Figure 1). That is, the

Table 1

The Association Between Stress-Induced ${ }^{18}$ F]fallypride Displacement (PET) and Psychotic Reactivity to Daily Life Stress, With and Without Three-Way Interaction With Group Status

\begin{tabular}{|c|c|c|c|c|c|c|c|c|}
\hline & \multicolumn{4}{|c|}{ Random intercept } & \multicolumn{4}{|c|}{ Random intercept + slope } \\
\hline & OR & $\mathrm{Z}$ & OR $95 \%$ CI & $p$-value & OR & $\mathrm{Z}$ & OR $95 \% \mathrm{CI}$ & $p$-value \\
\hline \multicolumn{9}{|c|}{ Two-way interaction ${ }^{\mathrm{a}}$} \\
\hline L VMPFC & .51 & -1.88 & .25 to 1.02 & .06 & .44 & -1.38 & .14 to 1.41 & .17 \\
\hline R VMPFC & .43 & -2.2 & .2 to .91 & $<.03^{*}$ & .35 & -1.67 & .1 to 1.2 & .09 \\
\hline \multicolumn{9}{|c|}{ Three-way interaction ${ }^{\mathrm{b}}$} \\
\hline L VMPFC & .37 & -1.07 & .06 to 2.28 & .28 & .39 & -1.03 & .06 to 2.35 & .3 \\
\hline R VMPFC & .28 & -1.31 & .04 to 1.87 & .19 & .29 & -1.29 & .04 to 1.91 & .2 \\
\hline
\end{tabular}

Note. Stress-induced $\left[{ }^{18} \mathrm{~F}\right]$ fallypride displacement (PET) moderates the association between momentary daily life stress and momentary psychosis. Adding the three-way interaction with group status revealed that the moderating effect was not different for $\mathrm{HV}$ and $\mathrm{HR}+\mathrm{VMPFC}=\mathrm{ventromedial}$ prefrontal cortex; OR = odds ratio.

a Two-way interaction: moderating effect of stress-induced $\left[{ }^{18} \mathrm{~F}\right]$ fallypride displacement on the association between momentary daily life stress and momentary psychosis. ${ }^{\mathrm{b}}$ Three-way interaction: is the moderating effect of stress-induced [ $\left.{ }^{18} \mathrm{~F}\right]$ fallypride displacement on the association between momentary daily life stress and momentary psychosis different for $\mathrm{HV}$ and $\mathrm{HR}+$ ?

* Exceeding $p$ (corrected) threshold of $p=.025$. 
odds of experiencing momentary psychotic symptoms when momentary daily life stress increased by one unit were greater for those with low stress-induced $\left[{ }^{18} \mathrm{~F}\right]$ fallypride displacement than for those with high stress-induced $\left[{ }^{18} \mathrm{~F}\right]$ fallypride displacement (see Figure 1). To further inspect this result, the proportion of prompts during which momentary psychotic experiences were present were plotted for each value of momentary daily life stress. Data were plotted on the basis of stress-induced $\left[{ }^{18} \mathrm{~F}\right]$ fallypride displacement in right VMPFC and were divided by their tertiles, creating tertile groups (see Figure 2). The bottom tertile (lowest stress-induced $\left[{ }^{18} \mathrm{~F}\right]$ fallypride displacement, indicative of low DAergic activity) showed the most psychotic experiences at low and high levels of daily life stress, middle and high tertiles demonstrated much less momentary psychotic experiences and/or only when daily life stress was high (see Figure 2). $\mathrm{BP}_{\mathrm{ND}}$ estimated over the complete paradigm did not moderate the association between momentary daily life stress and momentary psychotic experiences (random intercept VMPFC left: $\mathrm{Z}=.17$; $\mathrm{B}=-.66$; $95 \%$ CI $[-1.61$ to .29]; $p=.17$, VMPFC right: $\mathrm{Z}=-1.5$; $\mathrm{B}=-.7 ; 95 \% \mathrm{CI}[-1.61$ to .21$] ; p=.13$ ) (random intercept + slope VMPFC left: $\mathrm{Z}=-1 ; \mathrm{B}=-.78 ; 95 \% \mathrm{CI}[-2.32$ to .75]; $p=.32$, VMPFC right: $\mathrm{Z}=-1.22 ; \mathrm{B}=-.92 ; 95 \% \mathrm{CI}[-2.4$ to $.55] ; p=.22)$.

\section{Is the Association Between Stress-Induced} $\left[{ }^{18}\right.$ F] fallypride Displacement (PET) and Psychotic Reactivity to Daily Life Stress (ESM) Moderated by Group?

Exploratory random intercept and random intercept + random slope models revealed no large or significant three-way interaction between group, stress-induced VMPFC $\left[{ }^{18} \mathrm{~F}\right]$ fallypride displacement and daily life stress in the model of momentary psychotic symptoms. This suggested that the association between stress-

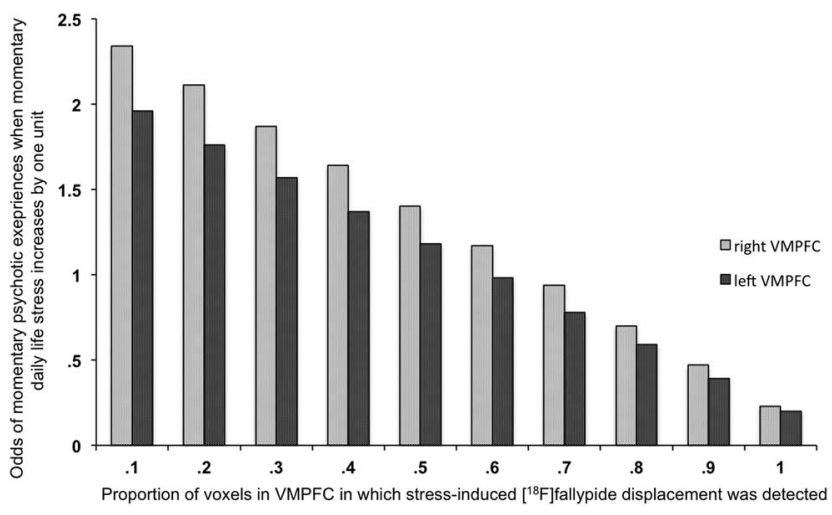

Figure 1. Odds ratios of momentary psychotic symptoms on the basis of the DAergic stress response in VMPFC. Predicted plot: regardless of status $(\mathrm{HV}, \mathrm{HR}+)$, individuals with low stress-induced $\left[{ }^{18} \mathrm{~F}\right]$ fallypride displacement in right $(\mathrm{p}=.03)$ and left $(\mathrm{p}=.06)$ VMPFC had increased chances of experiencing momentary psychotic symptoms when momentary daily life stress increased by one unit, compared with those that showed high stress-induced $\left[{ }^{18} \mathrm{~F}\right]$ fallypride displacement in right and left VMPFC. Please note that the distribution on the $x$-axis approximates the distribution of the actual data. Odds ratios were based on random intercept models. $\mathrm{p}=$ probability.

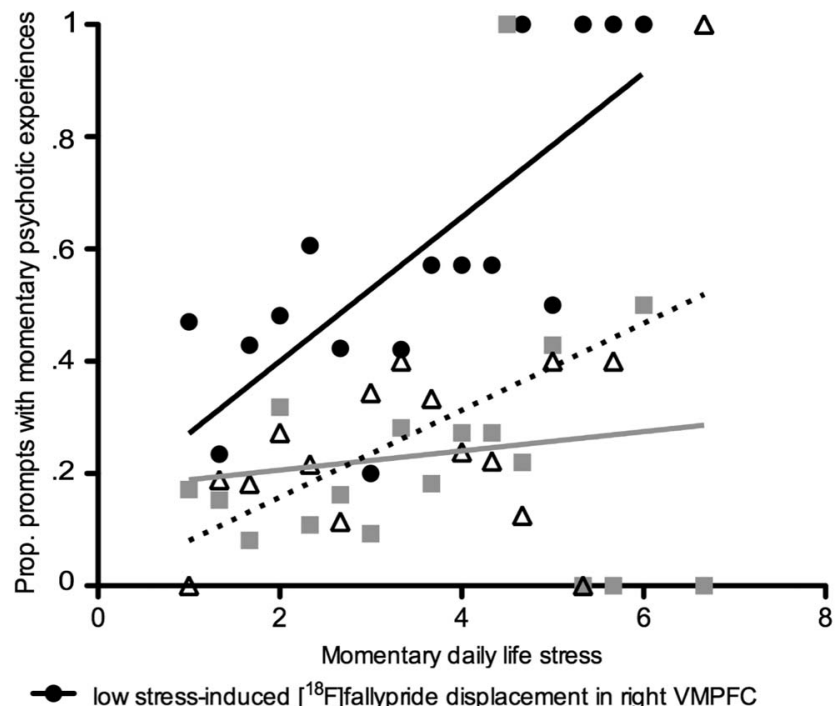

- medium stress-induced $\left[{ }^{18} \mathrm{~F}\right]$ fallypride displacement in right VMPFC

-A- high stress-induced $\left[{ }^{18} \mathrm{~F}\right]$ fallypride displacement in right VMPFC

Figure 2. Association between momentary psychotic symptoms (as a proportion of all prompts) and momentary daily life stress on the basis of the DAergic stress response in right VMPFC. Although the lowest tertile shows high proportions of psychotic symptoms, which seem to increase as daily life stress increases, middle and high tertiles show less psychotic symptoms, which are only moderately present at a high level of daily life stress.

induced $\left[{ }^{18} \mathrm{~F}\right]$ fallypride displacement in the lab and psychotic reactivity to daily life stress, assessed with ESM, was not different for HR+ and HV (see Table 1).

Visual inspection revealed that the proportion of completed prompts during which momentary psychotic experiences were present for each value of daily life stress (on the basis of $\left[{ }^{18} \mathrm{~F}\right]$ fallypride displacement in right VMPFC) was similar for $\mathrm{HR}+$ and $\mathrm{HV}$. There was also no significant three-way interaction between group, $\mathrm{BP}_{\mathrm{ND}}$ estimated over the complete paradigm and daily life stress in the model of momentary psychotic symptoms (random intercept VMPFC left: $\mathrm{Z}=-1.03 ; \mathrm{B}=-1.2 ; 95 \% \mathrm{CI}[-3.58$ to 1.11] $p=.73$, VMPFC right: $\mathrm{Z}=-1.18 ; \mathrm{B}=-1.47 ; 95 \% \mathrm{CI}$ [-3.93 to .98]; $p=.24$ ) (random intercept + slope VMPFC left: $\mathrm{Z}=-1.38 ; \mathrm{B}=-2.98 ; 95 \% \mathrm{CI}[-7.22$ to 1.25$] ; p=.17$, VMPFC right: $\mathrm{Z}=-1.36 ; \mathrm{B}=-2.91 ; 95 \% \mathrm{CI}[-7.11$ to 1.28$]$; $p=.17)$.

\section{Discussion}

In the current study, we combined PET neuroimaging with real life behavioral assessments in the investigation of subclinical psychotic symptoms. For this purpose, we investigated how levels of DAergic activity in response to a lab stressor were correlated with the individual's appraised level of stress and subclinical psychotic symptoms in daily life situations.

In the whole sample, VMPFC DAergic activity in response to a psychosocial stressor (assessed with $\left[{ }^{18} \mathrm{~F}\right]$ fallypride PET) was predictive of subclinical psychotic reactivity to daily life stress (assessed with ESM). More specifically, as stress-induced $\left[{ }^{18} \mathrm{~F}\right]$ fally- 
pride displacement in VMPFC decreased, indicative of attenuated stress-induced DAergic activity, psychotic reactivity to daily life stress increased. This association, however, remained restricted to the right VMPFC; the left VMPFC showed a similar trend that did not reach significance. Contrary to expectations, no differences between $\mathrm{HV}$ and $\mathrm{HR}+$ in moderation of psychotic reactivity to daily life stress by stress-induced right VMPFC DAergic activity were observed. We expected psychotic reactivity to daily life stress and stress-induced DAergic activity to correlate more strongly in $\mathrm{HR}+$ than $\mathrm{HV}$ based on previous work showing that $\mathrm{HR}+$ are more sensitive to daily life stress (Collip et al., 2011; MyinGermeys et al., 2005b). However, it should be noted that three-way interaction analyses to investigate group $(\mathrm{HV}, \mathrm{HR}+)$ differences were exploratory in nature and subtle differences might be observed with increased sample sizes. Replication with larger sample sizes is, therefore, important. In the final paragraph, we discuss the absence of this three-way interaction.

By combining ESM with PET neuroimaging, this study attempted to provide preliminary evidence for plausible links between indexes of brain function and experience of daily life emotions, as has been shown before (Barrett, Bliss-Moreau, Duncan, Rauch, \& Wright, 2007; Lopez, Hofmann, Wagner, Kelley, \& Heatherton, 2014; Morelli, Rameson, \& Lieberman, 2014). The use of assessments of person-environment interactions through experience sampling may provide insights and add ecological validity to phenomena that are studied in the lab, but should be interpreted in the context of real life.

\section{Stress and Psychosis: A Case of Person-Environment Interaction}

Epidemiological studies in the general population have demonstrated a strong association between (subclinical) psychotic symptoms and repeated exposure to significant stress-producing life events (Kelleher et al., 2013; Read et al., 2001; Varese et al., 2012). These findings imply an important role for the environment in the development of psychopathology, although the true nature of the relationship remains unknown.

Experience sampling studies assessing the experiential meaning of stress aimed to bridge this gap by studying the dynamics of psychopathology in the context of daily life, as was done in the current study. The experience of daily life stress was found to impact subclinical psychotic (Myin-Germeys et al., 2005a; MyinGermeys \& van Os, 2007; Oorschot, Kwapil, Delespaul, \& MyinGermeys, 2009) and emotional (Myin-Germeys \& van Os, 2007; Myin-Germeys et al., 2001) experiences across the population. Moreover, repeated exposure to childhood trauma or other severe stress-producing events increased the emotional reactivity to daily life stress (Lardinois, Lataster, Mengelers, Van Os, \& MyinGermeys, 2011; Myin-Germeys \& van Os, 2007). This is in line with the diathesis stress model (Walker \& Diforio, 1997) and suggests a pattern of sensitization by which repeated exposure to stressors may give rise to a lasting behavioral liability.

The focus on person-environment interactions is relevant for brain research as well. The brain does not operate in a void (Fuchs $\&$ Schlimme, 2009). The role of the brain can only be understood by investigating the way it is involved in person-environment interactions. The use of a psychosocial stress challenge (MIST; Pruessner et al. (2004) in PET paradigms was a first attempt to introduce a contextual variable in the study of DA in relation to stress, as opposed to metabolic stress (Adler et al., 2000). Although previous studies using the MIST have reported differences in biological parameters (e.g., changes in indexes of striatal DA transmission between control and experimental condition) (Pruessner et al., 2004; Soliman et al., 2008), Lataster and colleagues reported that aberrant stress-induced DA signaling in VMPFC was associated with increased feelings of subjective stress in response to the psychosocial stress challenge, providing insights into how these stress-induced changes in neurotransmitter activity are associated with subjective experiences (Lataster et al., 2014). The current study aimed to take this one step further by integrating the findings of this psychosocial stress PET paradigm with real life experiences in interaction with the context. We showed that right VMPFC DAergic activity in response to a lab stressor moderates psychotic reactivity to daily life stress. Based on these results, we speculate that alterations in the DAergic stress response could play a role in the experience of daily life stress. Still, the preliminary and unilateral nature of these findings warrants caution in interpretation. Of interest to the authors, aberrant stress-related behavior and experiences assessed with ESM seemed to be associated with the DAergic stress response in right VMPFC, but not with indices of the DA system collected over the whole paradigm, suggesting that functional brain processes specifically may be useful in combination with ESM assessments, as has also been shown before (Barrett et al., 2007; Lopez et al., 2014; Morelli et al., 2014).

This study provides hints on what the experiential meaning of altered DA transmission may be, by correlating this brain process with real-life experience-as-interaction. The integrative approach presented here could be of relevance for the broader scope of neuroimaging research in psychopathology. Standard data-focused methods of brain investigations are increasingly met with criticism. A common complaint is that such research is "blind" or "mindless" (Satel \& Lilienfeld, 2013). A combination of functional neuroimaging and ESM might prove a way forward to come to a richer understanding of neural measures, by "putting brain, body and world together again" (Clark, 1997).

\section{Neurochemical Processes Underlying Psychotic Reactivity to Daily Life Stress}

As to the exact neurobiological pathway involved in psychotic reactivity to daily life stress, it remains speculative and complex. Animal models show that exposure to a stressor affects DAergic activity in mesolimbic and cortical areas (Abercrombie, Keefe, DiFrischia, \& Zigmond, 1989; Roth, Tam, Ida, Yang, \& Deutch, 1988; Tidey \& Miczek, 1996). Moreover, manipulation of the DA system suggests an intricately linked DAergic stress system, potentially via a mesocorticolimbic pathway; alterations in frontal DAergic function in rodents are associated with aberrations in stress-related behavior (Scornaiencki, Cantrup, Rushlow, \& Rajakumar, 2009) and altered neurotransmitter activity in the nucleus accumbens (Deutch, Clark, \& Roth, 1990; King, Zigmond, \& Finlay, 1997). In healthy and clinical samples, psychological stress-induced changes in striatal and extrastriatal DAergic activity have repeatedly been demonstrated to be associated with physiological (Lataster et al., 2011; Mizrahi et al., 2012; Pruessner et al., 2004; Soliman et al., 2008) and psychological parameters (Lataster 
et al., 2014), revealing the functional relevance of the DA system in the stress response. The association between psychotic reactivity to daily life stress and HVA, reported previously (Myin-Germeys et al., 2005b), and the observations in the current manuscript suggest the functional relevance of the DA system in psychotic reactivity to daily life stress. However, it is not likely that DA is the sole player in psychotic reactivity to daily life stress. First, the effects of a stressor on the DA system are moderated by glucocorticoid receptors (GR) (Barik et al., 2013; Niwa et al., 2013). Second, stress-induced changes in the DA system and hypothalamus-pituitary-adrenal (HPA) axis activity correlate strongly with each other (Lataster et al., 2011; Mizrahi et al., 2013; Pruessner et al., 2004). Third, cortisol levels and psychotic reactivity in response to the experience of daily life stress are associated (Collip et al., 2011) and volumetric changes in brain areas that constitute the HPA axis are associated with behavioral (Collip et al., 2013a; Habets et al., 2012) and cortisol stress reactivity (Collip et al., 2013a) in daily life. Thus, studies that have included ecological assessment strategies all seem to point toward a central role for the HPA axis and DAergic activity in stress-reactivity in daily life. Given that (a) DAergic and HPA axis activity in response to stress (Lataster et al., 2011; Mizrahi et al., 2012; Pruessner et al., 2004) and following a 2-deoxyglucose challenge (Breier, Davis, Buchanan, Moricle, \& Munson, 1993) are correlated; and (b) that stress-induced changes in the DA system depend on GR activity (Barik et al., 2013; Niwa et al., 2013), there is sufficient evidence to suggest that cross-communication between these two systems may serve an essential role in psychotic reactivity to daily life stress. In other words, the expression of psychotic reactivity to daily life stress as a liability for psychosis may be dependent on, but not limited to, the interactions between these two systems.

\section{The DA System and Psychotic Reactivity to Daily Life Stress: Implications for the Diathesis Stress-Model}

In the previous paragraph we argued that both DAergic and HPA axis interactions may serve an important role in psychotic reactivity to daily life stress. It is interesting to speculate that the observed association between stress-induced right VMPFC DAergic activity and psychotic reactivity to stress may hint at process of sensitization for psychosis: those repeatedly exposed to (minor) stressors show abnormal stress-induced DAergic activity and psychotic reactivity to stress. This would be in line with studies showing that repeated exposure to stressors produces changes in the DAergic (Burke, Forster, Novick, Roberts, \& Watt, 2013; Watt et al., 2013) and glucocorticoid system (Walker \& Diforio, 1997). Moreover, repeated exposure to stress such as childhood trauma or life events also increases behavioral reactivity to stress (Collip, Myin-Germeys, Van Winkel, \& van Os, 2009; Lardinois et al., 2011; Myin-Germeys, Krabbendam, Delespaul, \& Van Os, 2003). Finally, decreased pituitary volume is associated with progressive increases in aberrant stress reactivity across the psychosis continuum (Habets et al., 2012), suggesting that as individuals move toward the far right of the psychosis spectrum, they become more sensitive to daily life stressors as measured by their appraisal of stress. Thus, sensitization for psychosis after repeated exposure to stressors may be reflected in lasting neurobiological changes, among others in the DA system, and abnormal behavioral reactivity to stress.
Although our sample size was limited, the association between psychotic reactivity to daily life stress and stress-related DAergic activity seemed similar for $\mathrm{HV}$ and $\mathrm{HR}+$. This may indicate that stress sensitization is an environmental process, unrelated to genetic risk for psychosis. However, this seems unlikely, given that genetic risk for psychosis increases aberrant behavioral reactivity to stress (Myin-Germeys \& van Os, 2007) and is associated with cortisol (Collip et al., 2011) and HVA levels (Myin-Germeys et al., 2005b). Moreover, the work mentioned above (Collip et al., 2013a; Habets et al., 2012) suggests a link between psychotic reactivity to daily life stress and progressive brain changes across the psychosis spectrum. In light of the small sample size and previous work (Collip et al., 2013a; Habets et al., 2012), we suspect that subtle differences between $\mathrm{HV}$ and $\mathrm{HR}+$ may become apparent with larger sample sizes. Although we were able to demonstrate preliminary evidence for an association between the DAergic stress response and psychotic reactivity to daily life stress, the need for replication with larger sample sizes is essential.

\section{Strengths and Limitations}

Key hypotheses were investigated in a relatively small sample. Although the sample is representational of a PET sample, ESM hypotheses are often investigated in larger samples (Oorschot et al., 2009). However, the repeated nature of ESM, with up to a maximum of 60 repeated measures per person, yields a very powerful estimate, even with a modest sample size such as the one presented in the current and other studies (So et al., 2013).

Important to the authors, the data collected for the purposes in the manuscript was cross-sectional in nature. Therefore, any conclusions regarding temporal direction of the effects were not possible. Furthermore, our modest sample size may explain why the moderating effect of stress-related VMPFC DAergic activity on psychotic reactivity to daily life stress remained restricted to the right VMPFC, although the left VMPFC demonstrated a similar nonsignificant direction. Furthermore, the nonsignificant, yet similar, direction of these associations in stricter models hints at a power problem for more complex analyses, such as the exploratory three-way interaction.

Although random intercept + slope models might be too conservative for the current study and indicate a Type II error, replication studies with a larger sample size are important. Replication with larger samples may allow the detection of subtle changes between $\mathrm{HV}$ and $\mathrm{HR}+$, groups that have been demonstrated to differ in other ecological assessment studies (Collip et al., 2011; Myin-Germeys et al., 2005b).

Both PET and ESM have their own strengths and limitations. The PET strengths and limitations of the current study, including outcome measures and designs have been discussed in detail previously (Hernaus et al., 2013; Lataster et al., 2014). The strengths include the laboratory stressor with ecological validity (Lataster et al., 2014; Pruessner et al., 2004) and avoidance of session effects (Lataster et al., 2014); drawbacks may include strict order of conditions and cognition-induced DAergic activity (Lataster et al., 2011). The ESMs strength lies in investigating subtle changes in daily life behavior.

Although the quality of paper and pencil ESM methods has been called into question (Stone, Shiffman, Schwartz, Broderick, \& Hufford, 2003), evidence suggests that paper and pencil ESM is 
comparable with the more recent electronic diary in terms of compliance rates, research findings and psychometric features, suggesting both are equally suitable to assess daily life experiences (Green, Rafaeli, Bolger, Shrout, \& Reis, 2006; Jacobs et al., 2005). ESM limitations include the repetitive nature of the assessment (Oorschot et al., 2009).

\section{References}

Abercrombie, E. D., Keefe, K. A., DiFrischia, D. S., \& Zigmond, M. J. (1989). Differential effect of stress on in vivo dopamine release in striatum, nucleus accumbens, and medial frontal cortex. Journal of Neurochemistry, 52, 1655-1658. http://dx.doi.org/10.1111/j.1471-4159 .1989.tb09224.x

Adler, C. M., Elman, I., Weisenfeld, N., Kestler, L., Pickar, D., \& Breier, A. (2000). Effects of acute metabolic stress on striatal dopamine release in healthy volunteers. Neuropsychopharmacology, 22, 545-550. http:// dx.doi.org/10.1016/S0893-133X(99)00153-0

American Psychiatric Association. (2000). Diagnostic and Statistical Manual of Mental Disorders (4th Edition, Text Revision). Washington, DC: American Psychiatric Association.

Barik, J., Marti, F., Morel, C., Fernandez, S. P., Lanteri, C., Godeheu, G., . . . Tronche, F. (2013). Chronic stress triggers social aversion via glucocorticoid receptor in dopaminoceptive neurons. Science, 339, 332335. http://dx.doi.org/10.1126/science. 1226767

Barrett, L. F., Bliss-Moreau, E., Duncan, S. L., Rauch, S. L., \& Wright, C. I. (2007). The amygdala and the experience of affect. Social Cognitive and Affective Neuroscience, 2, 73-83. http://dx.doi.org/10.1093/ scan/ns1042

Breier, A., Davis, O. R., Buchanan, R. W., Moricle, L. A., \& Munson, R. C. (1993). Effects of metabolic perturbation on plasma homovanillic acid in schizophrenia. Relationship to prefrontal cortex volume. Archives of General Psychiatry, 50, 541-550. http://dx.doi.org/10.1001/ archpsyc.1993.01820190043005

Burke, A. R., Forster, G. L., Novick, A. M., Roberts, C. L., \& Watt, M. J. (2013). Effects of adolescent social defeat on adult amphetamineinduced locomotion and corticoaccumbal dopamine release in male rats. Neuropharmacology, 67, 359-369. http://dx.doi.org/10.1016/ j.neuropharm.2012.11.013

Ceccarini, J., Vrieze, E., Koole, M., Muylle, T., Bormans, G., Claes, S., \& Van Laere, K. (2012). Optimized in vivo detection of dopamine release using 18F-fallypride PET. Journal of Nuclear Medicine, 53, 1565-1572. http://dx.doi.org/10.2967/jnumed.111.099416

Christian, B. T., Lehrer, D. S., Shi, B., Narayanan, T. K., Strohmeyer, P. S., Buchsbaum, M. S., \& Mantil, J. C. (2006). Measuring dopamine neuromodulation in the thalamus: Using [F-18]fallypride PET to study dopamine release during a spatial attention task. Neuroimage, 31, 139152.

Clark, A. (1997). Being there: Putting brain, body and world together again. Cambridge, MA: The MIT Press.

Collip, D., Habets, P., Marcelis, M., Gronenschild, E., Lataster, T., Lardinois, M., . . Myin-Germeys, I. (2013a). Hippocampal volume as marker of daily life stress sensitivity in psychosis. Psychological Medicine, 43, 1377-1387. http://dx.doi.org/10.1017/S003329171200219X

Collip, D., Myin-Germeys, I., Van Winkel, R., \& van Os, J. (2009). Stress and psychosis: Is sensitisation the underlying mechanism? Tijdschrift voor Psychiatrie, 51, 559-567.

Collip, D., Nicolson, N. A., Lardinois, M., Lataster, T., van Os, J., \& Myin-Germeys, I., \& the G. R. O. U. P. (2011). Daily cortisol, stress reactivity and psychotic experiences in individuals at above average genetic risk for psychosis. Psychological Medicine, 41, 2305-2315. http://dx.doi.org/10.1017/S0033291711000602

Collip, D., Wigman, J. T., Myin-Germeys, I., Jacobs, N., Derom, C., Thiery, E., . . . van Os, J. (2013b). From epidemiology to daily life:
Linking daily life stress reactivity to persistence of psychotic experiences in a longitudinal general population study. PLOS ONE, 8, e62688. http://dx.doi.org/10.1371/journal.pone.0062688

Delespaul, P. (1995). Assessing schizophrenia in daily life. Maastricht: Universitaire Pers.

Demjaha, A., Murray, R. M., McGuire, P. K., Kapur, S., \& Howes, O. D. (2012). Dopamine synthesis capacity in patients with treatment-resistant schizophrenia. The American Journal of Psychiatry, 169, 1203-1210. http://dx.doi.org/10.1176/appi.ajp.2012.12010144

Deutch, A. Y., Clark, W. A., \& Roth, R. H. (1990). Prefrontal cortical dopamine depletion enhances the responsiveness of mesolimbic dopamine neurons to stress. Brain Research, 521, 311-315.

Egerton, A., Chaddock, C. A., Winton-Brown, T. T., Bloomfield, M. A., Bhattacharyya, S., Allen, P., . . . Howes, O. D. (2013). Presynaptic striatal dopamine dysfunction in people at ultra-high risk for psychosis: Findings in a second cohort. Biological Psychiatry, 74, 106-112. http:// dx.doi.org/10.1016/j.biopsych.2012.11.017

Fuchs, T., \& Schlimme, J. E. (2009). Embodiment and psychopathology: A phenomenological perspective. Current Opinion in Psychiatry, 22, 570575. http://dx.doi.org/10.1097/YCO.0b013e3283318e5c

Green, A. S., Rafaeli, E., Bolger, N., Shrout, P. E., \& Reis, H. T. (2006) Paper or plastic? Data equivalence in paper and electronic diaries. Psychological Methods, 11, 87-105. http://dx.doi.org/10.1037/1082989X.11.1.87

Habets, P., Collip, D., Myin-Germeys, I., Gronenschild, E., van Bronswijk, S., Hofman, P., . . . Marcelis, M. (2012). Pituitary volume, stress reactivity and genetic risk for psychotic disorder. Psychological Medicine, 42, 1523-1533. http://dx.doi.org/10.1017/S0033291711002728

Hall, H., Farde, L., \& Sedvall, G. (1988). Human dopamine receptor subtypes-In vitro binding analysis using 3H-SCH 23390 and 3Hraclopride. Journal of Neural Transmission, 73, 7-21. http://dx.doi.org/ 10.1007/BF01244618

Heins, M., Simons, C., Lataster, T., Pfeifer, S., Versmissen, D., Lardinois, M., . . Myin-Germeys, I. (2011). Childhood trauma and psychosis: A case-control and case-sibling comparison across different levels of genetic liability, psychopathology, and type of trauma. The American Journal of Psychiatry, 168, 1286-1294.

Hernaus, D., Collip, D., Lataster, J., Ceccarini, J., Kenis, G., Booij, L., . . Myin-Germeys, I. (2013). COMT Val158Met genotype selectively alters prefrontal $[18 \mathrm{~F}]$ fallypride displacement and subjective feelings of stress in response to a psychosocial stress challenge. PLOS ONE, 8, e65662. http://dx.doi.org/10.1371/journal.pone.0065662

Howes, O., Bose, S., Turkheimer, F., Valli, I., Egerton, A., Stahl, D., . . McGuire, P. (2011a). Progressive increase in striatal dopamine synthesis capacity as patients develop psychosis: A PET study. Molecular Psychiatry, 16, 885-886. http://dx.doi.org/10.1038/mp.2011.20

Howes, O. D., Bose, S. K., Turkheimer, F., Valli, I., Egerton, A., Valmaggia, L. R., . . . McGuire, P. (2011b). Dopamine synthesis capacity before onset of psychosis: A prospective [18F]-DOPA PET imaging study. The American Journal of Psychiatry, 168, 1311-1317. http://dx.doi.org/10.1176/appi.ajp.2011.11010160

Howes, O. D., Kambeitz, J., Kim, E., Stahl, D., Slifstein, M., AbiDargham, A., \& Kapur, S. (2012). The nature of dopamine dysfunction in schizophrenia and what this means for treatment. Archives of General Psychiatry, 69, 776-786. http://dx.doi.org/10.1001/archgenpsychiatry .2012 .169

Howes, O. D., \& Kapur, S. (2009). The dopamine hypothesis of schizophrenia: Version III-The final common pathway. Schizophrenia Bulletin, 35, 549-562. http://dx.doi.org/10.1093/schbul/sbp006

Innis, R. B., Cunningham, V. J., Delforge, J., Fujita, M., Gjedde, A., Gunn, R. N., . . C Carson, R. E. (2007). Consensus nomenclature for in vivo imaging of reversibly binding radioligands. Journal of Cerebral Blood Flow and Metabolism, 27, 1533-1539. http://dx.doi.org/10.1038/ sj.jcbfm.9600493 
Jacobs, N., Nicolson, N. A., Derom, C., Delespaul, P., van Os, J., \& Myin-Germeys, I. (2005). Electronic monitoring of salivary cortisol sampling compliance in daily life. Life Sciences, 76, 2431-2443. http:// dx.doi.org/10.1016/j.lfs.2004.10.045

Kegeles, L. S., Abi-Dargham, A., Frankle, W. G., Gil, R., Cooper, T. B., Slifstein, M., . . . Laruelle, M. (2010). Increased synaptic dopamine function in associative regions of the striatum in schizophrenia. Archives of General Psychiatry, 67, 231-239. http://dx.doi.org/10.1001/ archgenpsychiatry.2010.10

Kegeles, L. S., Slifstein, M., Frankle, W. G., Xu, X., Hackett, E., Bae, S. A., ... Abi-Dargham, A. (2008). Dose-occupancy study of striatal and extrastriatal dopamine D2 receptors by aripiprazole in schizophrenia with PET and [18F]fallypride. Neuropsychopharmacology, 33, 31113125. http://dx.doi.org/10.1038/npp.2008.33

Kelleher, I., Keeley, H., Corcoran, P., Ramsay, H., Wasserman, C., Carli, V., . . . Cannon, M. (2013). Childhood trauma and psychosis in a prospective cohort study: Cause, effect, and directionality. The American Journal of Psychiatry, 170, 734-741. http://dx.doi.org/10.1176/appi.ajp .2012 .12091169

King, D., Zigmond, M. J., \& Finlay, J. M. (1997). Effects of dopamine depletion in the medial prefrontal cortex on the stress-induced increase in extracellular dopamine in the nucleus accumbens core and shell. Neuroscience, 77, 141-153.

Kirschbaum, C., Pirke, K. M., \& Hellhammer, D. H. (1993). The 'Trier Social Stress Test': A tool for investigating psychobiological stress responses in a laboratory setting. Neuropsychobiology, 28, 76-81.

Kopin, I. J., Bankiewicz, K. S., \& Harvey-White, J. (1988). Assessment of brain dopamine metabolism from plasma HVA and MHPG during debrisoquin treatment: Validation in monkeys treated with MPTP. Neuropsychopharmacology, 1, 119-125. http://dx.doi.org/10.1016/0893133X(88)90003-6

Kramer, I., Simons, C. J., Wigman, J. T., Collip, D., Jacobs, N., Derom, C., . . Wichers, M. (2013). Time-lagged moment-to-moment interplay between negative affect and paranoia: New insights in the affective pathway to psychosis. [Advance online publication]. Schizophrenia Bulletin.

Lammertsma, A. A., \& Hume, S. P. (1996). Simplified reference tissue model for PET receptor studies. Neuroimage, 4, 153-158.

Lardinois, M., Lataster, T., Mengelers, R., Van Os, J., \& Myin-Germeys, I. (2011). Childhood trauma and increased stress sensitivity in psychosis. Acta Psychiatrica Scandinavica, 123, 28-35. http://dx.doi.org/10.1111/ j.1600-0447.2010.01594.x

Laruelle, M., \& Abi-Dargham, A. (1999). Dopamine as the wind of the psychotic fire: New evidence from brain imaging studies. Journal of Psychopharmacology, 13, 358-371. http://dx.doi.org/10.1177/ 026988119901300405

Laruelle, M., Abi-Dargham, A., Gil, R., Kegeles, L., \& Innis, R. (1999). Increased dopamine transmission in schizophrenia: Relationship to illness phases. Biological Psychiatry, 46, 56-72. http://dx.doi.org/ 10.1016/S0006-3223(99)00067-0

Lataster, J., Collip, D., Ceccarini, J., Haas, D., Booij, L., van Os, J., . . Myin-Germeys, I. (2011). Psychosocial stress is associated with in vivo dopamine release in human ventromedial prefrontal cortex: A positron emission tomography study using $\left[{ }^{18} \mathrm{~F}\right]$ fallypride. NeuroImage, 58, 1081-1089. http://dx.doi.org/10.1016/j.neuroimage.2011.07.030

Lataster, J., Collip, D., Ceccarini, J., Hernaus, D., Haas, D., Booij, L., . . . Myin-Germeys, I. (2014). Familial liability to psychosis is associated with attenuated dopamine stress signaling in ventromedial prefrontal cortex. Schizophrenia Bulletin, 40, 66-77. http://dx.doi.org/10.1093/ schbul/sbs 187

Lataster, T., Collip, D., Lardinois, M., van Os, J., \& Myin-Germeys, I. (2010). Evidence for a familial correlation between increased reactivity to stress and positive psychotic symptoms. Acta Psychiatrica Scandi- navica, 122, 395-404. http://dx.doi.org/10.1111/j.1600-0447.2010 .01566.x

Lataster, T., Valmaggia, L., Lardinois, M., van Os, J., \& Myin-Germeys, I. (2013). Increased stress reactivity: A mechanism specifically associated with the positive symptoms of psychotic disorder. Psychological Medicine, 43, 1389-1400. http://dx.doi.org/10.1017/S0033291712002279

Linscott, R. J., \& van Os, J. (2013). An updated and conservative systematic review and meta-analysis of epidemiological evidence on psychotic experiences in children and adults: On the pathway from proneness to persistence to dimensional expression across mental disorders. Psychological Medicine, 43, 1133-1149. http://dx.doi.org/10.1017/ S0033291712001626

Lopez, R. B., Hofmann, W., Wagner, D. D., Kelley, W. M., \& Heatherton, T. F. (2014). Neural predictors of giving in to temptation in daily life. [Advance online publication]. Psychological Science, 25, 1337-1344. http://dx.doi.org/10.1177/0956797614531492

McGuffin, P., Farmer, A., \& Harvey, I. (1991). A polydiagnostic application of operational criteria in studies of psychotic illness. Development and reliability of the OPCRIT system. Archives of General Psychiatry, 48, 764-770. http://dx.doi.org/10.1001/archpsyc.1991.01810320088015

Mizrahi, R., Addington, J., Rusjan, P. M., Suridjan, I., Ng, A., Boileau, I., ... Wilson, A. A. (2012). Increased stress-induced dopamine release in psychosis. Biological Psychiatry, 71, 561-567. http://dx.doi.org/ 10.1016/j.biopsych.2011.10.009

Mizrahi, R., Kenk, M., Suridjan, I., Boileau, I., George, T. P., McKenzie, K., . . Rusjan, P. (2013). Stress-induced dopamine response in subjects at clinical high risk for schizophrenia with and without concurrent cannabis use. [Advance online publication]. Neuropsychopharmacology.

Montgomery, A. J., Mehta, M. A., \& Grasby, P. M. (2006). Is psychological stress in man associated with increased striatal dopamine levels?: A [11C]raclopride PET study. Synapse, 60, 124-131. http://dx.doi.org/ 10.1002/syn.20282

Morelli, S. A., Rameson, L. T., \& Lieberman, M. D. (2014). The neural components of empathy: Predicting daily prosocial behavior. Social Cognitive and Affective Neuroscience, 9, 39-47. http://dx.doi.org/ $10.1093 / \mathrm{scan} / \mathrm{nss} 088$

Mukherjee, J., Christian, B. T., Dunigan, K. A., Shi, B., Narayanan, T. K., Satter, M., \& Mantil, J. (2002). Brain imaging of 18F-fallypride in normal volunteers: Blood analysis, distribution, test-retest studies, and preliminary assessment of sensitivity to aging effects on dopamine D-2/D-3 receptors. Synapse, 46, 170-188. http://dx.doi.org/10.1002/syn .10128

Myin-Germeys, I., Delespaul, P., \& van Os, J. (2005a). Behavioural sensitization to daily life stress in psychosis. Psychological Medicine, 35, 733-741. http://dx.doi.org/10.1017/S0033291704004179

Myin-Germeys, I., Krabbendam, L., Delespaul, P. A., \& Van Os, J. (2003). Do life events have their effect on psychosis by influencing the emotional reactivity to daily life stress? Psychological Medicine, 33, 327 333. http://dx.doi.org/10.1017/S0033291702006785

Myin-Germeys, I., Marcelis, M., Krabbendam, L., Delespaul, P., \& van Os, J. (2005b). Subtle fluctuations in psychotic phenomena as functional states of abnormal dopamine reactivity in individuals at risk. Biological Psychiatry, 58, 105-110. http://dx.doi.org/10.1016/j.biopsych.2005.02 .012

Myin-Germeys, I., Oorschot, M., Collip, D., Lataster, J., Delespaul, P., \& van Os, J. (2009). Experience sampling research in psychopathology: Opening the black box of daily life. Psychological Medicine, 39, 1533 1547. http://dx.doi.org/10.1017/S0033291708004947

Myin-Germeys, I., \& van Os, J. (2007). Stress-reactivity in psychosis: Evidence for an affective pathway to psychosis. Clinical Psychology Review, 27, 409-424. http://dx.doi.org/10.1016/j.cpr.2006.09.005

Myin-Germeys, I., van Os, J., Schwartz, J. E., Stone, A. A., \& Delespaul, P. A. (2001). Emotional reactivity to daily life stress in psychosis. Archives of General Psychiatry, 58, 1137-1144. 
Nagano-Saito, A., Dagher, A., Booij, L., Gravel, P., Welfeld, K., Casey, K. F., . . . Benkelfat, C. (2013). Stress-induced dopamine release in human medial prefrontal cortex-18F-fallypride/PET study in healthy volunteers. Synapse, 67, 821-830. http://dx.doi.org/10.1002/syn.21700

Niwa, M., Jaaro-Peled, H., Tankou, S., Seshadri, S., Hikida, T., Matsumoto, Y., . . Sawa, A. (2013). Adolescent stress-induced epigenetic control of dopaminergic neurons via glucocorticoids. Science, 339, 335339. http://dx.doi.org/10.1126/science.1226931

Oorschot, M., Kwapil, T., Delespaul, P., \& Myin-Germeys, I. (2009). Momentary assessment research in psychosis. Psychological Assessment, 21, 498-505. http://dx.doi.org/10.1037/a0017077

Peerbooms, O., Rutten, B. P., Collip, D., Lardinois, M., Lataster, T., Thewissen, V., . . van Winkel, R. (2012). Evidence that interactive effects of COMT and MTHFR moderate psychotic response to environmental stress. Acta Psychiatrica Scandinavica, 125, 247-256. http://dx.doi.org/10.1111/j.1600-0447.2011.01806.x

Pruessner, J. C., Champagne, F., Meaney, M. J., \& Dagher, A. (2004). Dopamine release in response to a psychological stress in humans and its relationship to early life maternal care: A positron emission tomography study using [11C]raclopride. The Journal of Neuroscience, 24, 28252831. http://dx.doi.org/10.1523/JNEUROSCI.3422-03.2004

Read, J., Perry, B. D., Moskowitz, A., \& Connolly, J. (2001). The contribution of early traumatic events to schizophrenia in some patients: A traumagenic neurodevelopmental model. Psychiatry, 64, 319-345. http://dx.doi.org/10.1521/psyc.64.4.319.18602

Roth, R. H., Tam, S. Y., Ida, Y., Yang, J. X., \& Deutch, A. Y. (1988). Stress and the mesocorticolimbic dopamine systems. Annals of the New York Academy of Sciences, 537, 138-147. http://dx.doi.org/10.1111/ j.1749-6632.1988.tb42102.x

Satel, S., \& Lilienfeld, S. O. (2013). Brainwashed: The seductive appeal. New York, NY: Basic Books.

Schwartz, J. E., \& Stone, A. A. (1998). Strategies for analyzing ecological momentary assessment data. Health Psychology, 17, 6-16. http:// dx.doi.org/10.1037/0278-6133.17.1.6

Scornaiencki, R., Cantrup, R., Rushlow, W. J., \& Rajakumar, N. (2009). Prefrontal cortical D1 dopamine receptors modulate subcortical D2 dopamine receptor-mediated stress responsiveness. International Journal of Neuropsychopharmacol, 12, 1195-1208

So, S. H., Peters, E. R., Swendsen, J., Garety, P. A., \& Kapur, S. (2013). Detecting improvements in acute psychotic symptoms using experience sampling methodology. Psychiatry Research, 210, 82-88. http://dx.doi.org/10.1016/j.psychres.2013.05.010
Soliman, A., O’Driscoll, G. A., Pruessner, J., Holahan, A. L., Boileau, I., Gagnon, D., \& Dagher, A. (2008). Stress-induced dopamine release in humans at risk of psychosis: A [11C]raclopride PET study. Neuropsychopharmacology, 33, 2033-2041. http://dx.doi.org/10.1038/sj.npp .1301597

Stone, A. A., Shiffman, S., Schwartz, J. E., Broderick, J. E., \& Hufford, M. R. (2003). Patient compliance with paper and electronic diaries. Controlled Clinical Trials, 24, 182-199. http://dx.doi.org/10.1016/ S0197-2456(02)00320-3

Talairach, J., \& Tournoux, P. (1988). Co-planar stereotaxic atlas of the human brain. New York: Thieme.

Tidey, J. W., \& Miczek, K. A. (1996). Social defeat stress selectively alters mesocorticolimbic dopamine release: An in vivo microdialysis study. Brain Research, 721, 140-149. http://dx.doi.org/10.1016/00068993(96)00159-X

van Winkel, R., Stefanis, N. C., \& Myin-Germeys, I. (2008). Psychosocial stress and psychosis. A review of the neurobiological mechanisms and the evidence for gene-stress interaction. Schizophrenia Bulletin, 34, 1095-1105. http://dx.doi.org/10.1093/schbul/sbn101

Varese, F., Smeets, F., Drukker, M., Lieverse, R., Lataster, T., Viechtbauer, W., . . . Bentall, R. P. (2012). Childhood adversities increase the risk of psychosis: A meta-analysis of patient-control, prospective- and cross-sectional cohort studies. Schizophrenia Bulletin, 38, 661-671. http://dx.doi.org/10.1093/schbul/sbs050

Walker, E. F., \& Diforio, D. (1997). Schizophrenia: A neural diathesisstress model. Psychological Review, 104, 667-685. http://dx.doi.org/ 10.1037/0033-295X.104.4.667

Watt, M. J., Roberts, C. L., Scholl, J. L., Meyer, D. L., Miiller, L. C., Barr, J. L., . . Forster, G. L. (2013). Decreased prefrontal cortex dopamine activity following adolescent social defeat in male rats: Role of dopamine D receptors. [Advance online publication]. Psychopharmacology.

Woodward, N. D., Cowan, R. L., Park, S., Ansari, M. S., Baldwin, R. M., Li, R., . . Z Zald, D. H. (2011). Correlation of individual differences in schizotypal personality traits with amphetamine-induced dopamine release in striatal and extrastriatal brain regions. The American Journal of Psychiatry, 168, 418-426. http://dx.doi.org/10.1176/appi.ajp.2010 .10020165

Received February 18, 2014

Revision received August 27, 2014

Accepted August 28, 2014 